\title{
"PRENADA ESTABA LA ENCINA": \\ DE LOS NUEVOS NACIMIENTOS SIMBÓLICOS \\ SIN MADRE A LA INESPERADA \\ ARMONÍA PATERNO-FILIAL \\ EN LOS TRABAJOS DE PERSILES Y SIGISMUNDA
}

Los trabajos de Persiles y Sigismunda es la última novela de Cervantes, que se publica, póstumamente, en 1617. En ésta se narra el largo viaje, lleno de aventuras, de dos príncipes, Persiles y Sigismunda, quienes fingen ser hermanos (con los sobrenombres de Periandro y Auristela), para llegar a Roma y contraer matrimonio. La historia se divide en cuatro libros, con marcadas diferencias entre los primeros dos y los restantes, especialmente, en cuanto al papel que desempeña el narrador en ambos casos. En los primeros dos, apenas se hace presente, mientras que, en los últimos, amenaza con desplazar a los personajes. También, se percibe un cambio de tono, ya que en la segunda parte se acentúa el sentido realista, mientras disminuye la presencia de elementos maravillosos y la acumulación de aventuras ${ }^{1}$.

Cervantes utiliza la técnica de la novela bizantina (viajes, aventuras, naufragios, separaciones y encuentros), para crear una epopeya con el tema de la peregrinación ${ }^{2}$. Para escribir esta novela, Cervantes se inspira en Las etiópicas o Teágenes y Cariclea de Heliodoro, con quien cándidamente se compara: "Tras ellas, si la vida no me deja, te ofrezco Los trabajos de Persiles y Sigismunda, libro que se atreve a competir con Heliodoro, si ya por

1 Véase Javier González Rovira, La novela bizantina de la Edad de Oro, Gredos, Madrid, 1996, p. 231.

2 Cf. Alban Forcione, Cervantes' Christian romance. A study of Persiles y Sigismunda, Princeton University Press, Princeton, 1971. 
atrevida no sale con las manos en la cabeza"' . El argumento de Las etiópicas es bastante sencillo; lo complicado es la serie de historias intercaladas y sucesos imprevistos que ocurren a lo largo de la novela. Cariclea, joven sacerdotisa del templo de Apolo en Delfos, y Teágenes, príncipe tesalio, se enamoran a primera vista. Junto a Calasiris, sacerdote en Delfos, se trasladan a Egipto, luego de haberse jurado amor eterno y comprometerse en su castidad hasta el momento del matrimonio. Tras una serie de infortunios, los jóvenes son tomados prisioneros en Etiopía para sacrificarlos en un ritual. Cuando están a punto de ser sacrificados, la reina reconoce a Cariclea como su hija desaparecida. Los reyes etíopes acogen a la joven y se lleva a cabo el tan ansiado matrimonio ${ }^{4}$.

Cervantes supera o, al menos, altera su modelo en varios aspectos. En primer lugar, desde el punto de vista de la técnica narrativa, El Persiles presenta bastante más complejidad que Las etiópicas, por lo que requiere un lector muy atento. Las aventuras y los encuentros en el camino de los protagonistas se multiplican considerablemente: "La profusión de relatos en las Etiópicas se intensifica en el Persiles, hasta el punto de que conforman su arquitectura narrativa, a excepción quizás del libro cuarto" 5 . A ello hay que añadir, en contraste con la novela griega, que la geografía y el tiempo en El Persiles son mucho más cercanos y actuales (con la excepción de los primeros capítulos). Además, hay un notable distanciamiento irónico de Cervantes con respecto a ciertas convenciones y limitaciones del género. Como señala Stanislav Zimic: "Cervantes vio con perspicacia que el novelista bizantino [Heliodoro] la desvirtuaba [la técnica narrativa], abusando de ciertos recursos que para ser eficaces exigían moderación" ${ }^{6}$. Por otro lado, en la complejidad y la variedad psicológica de sus personajes, Cervantes resulta superior a Heliodoro, cuyos protagonistas acusaban ya un acartonamiento que anunciaba el agotamiento del género. Ello no impide que estén caracterizados como los héroes típicos de la novela: her-

3 Miguel de Cervantes, Los trabajos de Persiles y Sigismunda, EspasaCalpe, Madrid, 1968, p. 53. En adelante, cito en el cuerpo del texto, por esta edición, como Persiles, seguido de número de página.

${ }^{4}$ Heliodoro, Las etiópicas o Teágenes y Cariclea, Gredos, Madrid, 1979.

5 Isabel Lozano Renieblas, "Los relatos orales del Persiles", Cervantes, 22 (2002), p. 113.

6 "El Persiles como crítica de la novela bizantina", Acta Neophilológica, 1970, p. 52. 
mosos, castos y adornados de una sólida religiosidad cristiana, que culminan con su peregrinación para la celebración de su matrimonio en Roma.

En cuanto al tema de este estudio, en El Persiles aparece una amplia gama de figuras paternas y maternas. De hecho, Diana de Armas Wilson considera que: “The sterility of Don Quixote's circuitous journey gives way, in Cervantes's late experimental romance, to a rethoric of generativity: birth, copulation, and parenting are all tactical metaphors within a text whose final word is "posteriority"'"7. En esta obra, las relaciones paterno-filiales tienen un papel mucho más importante que en las anteriores. Como ocurre en La Galatea y en El Quijote, en esta novela, Cervantes presenta parejas de padres e hijas. En ninguno de los textos, curiosamente, aparece una pareja de padre e hijo. Nuevamente, en estos casos, se hace evidente la ausencia de la madre, algo que ya, como se sabe, es característico de la obra cervantina. Sin embargo, en este aspecto, no se puede afirmar que se trate de una total innovación del autor debido a que, como bien señala Emilie Bergmann: "Mothers are scarce and silent, if not completetly abscent, from the Comedias and early modern Spanish fiction and Lyric". Por su parte, Anne Cruz afirma:

Aunque cada vez más disminuido y conflictivo, el puesto que ocupa la figura de la madre no se pierde del todo de vista en la trayectoria de la literatura medieval. En cambio, en la literatura áurea, las pocas referencias a la madre terminan por destacar su ausencia... 9 .

Según la estudiosa, este hecho se debe, principalmente, a la desvalorización de la mujer, reforzada por los edictos de la Contrarreforma que manifiestan una ideología que rebaja a la mujer en todas sus facetas $(i d$.$) . En esta obra, aparecen dos$ casos de este tipo: Mauricio y Transila y el rey Policarpo y sus hijas, Sinforosa y Policarpa.

7 “Cervantes' Labors of Persiles: Working (in) the in between”, Literary Theory/ Renaissance Texts, Johns Hopkins University Press, Baltimore, 1986, p. 151.

8 "Family routes in Cervantes", Cervantes y su mundo, Reichenberger, Kassel, 2005, t. 3, p. 2.

${ }^{9}$ En su artículo, "La búsqueda de la madre: psicoanálisis y feminismo en la literatura del Siglo de Oro", Actas del XII Congreso de la Asociación Internacional de Hispanistas, 21-26 de agosto de 1995, Birmingham, 1998, p. 139. 
La primera pareja, Mauricio y Transila (parte 1), se asemeja mucho a la de Ricote y Ana Félix, en El Quijote, ya que tienen una relación en la que impera el amor y el respeto mutuo. Tras la muerte de su esposa, cuando Transila tiene dos años de nacida, Mauricio se da a la tarea de criarla solo: “...creció esta muchacha a mi sombra, porque le faltó la de su madre dos años después de nacida y a mí me faltó el arrimo de mi vejez y me sobró el cuidado de criar la hija" (Persiles, pp. 77-78). El padre, de carácter liberal, se preocupa mucho por el futuro de su hija y decide casarla, pero sólo con el consentimiento de ella: “...por parecerme acertado y aun conveniente que los padres casen a sus hijas con su beneplácito y gusto, pues no les dan compañía por un día, sino por todos aquellos que les durare la vida" (Persiles, p. 78). Sin duda, se trata de una actitud inusual, tomando en cuenta el dominio absoluto que ejercen los padres sobre los hijos en tiempos de Cervantes.

Como se tiene la oportunidad de apreciar, el autor es partidario de que los hijos tengan la libertad de escoger con quién casarse. Como señala Américo Castro: "[Cervantes] recibiría tales ideas de Italia, en el ambiente en el que se formaban los grandes pensadores del momento" 10 . Además, Mauricio se asemeja a otro padre extraordinario de la literatura española: el Pleberio de La Celestina. Pleberio considera que es necesario conocer el parecer de su hija, Melibea, acerca de un asunto tan importante como el matrimonio; a diferencia de su esposa, Alisa, quien opina que este asunto es de exclusiva incumbencia de los padres:

¿Debemos hablarlo a nuestra hija, debemos darle parte de tantos como me la piden, para que de su voluntad venga, para que diga cuál le agrada? Pues en esto las leyes dan libertad a los hombres y mujeres, aunque estén so el paterno poder, para elegir ${ }^{11}$.

Cervantes se hace eco de este discurso tan moderno y favorable a las mujeres. Cervantes parece mantenerse fiel a sus ideas con respecto a la necesaria participación de las mujeres al escoger con quién casarse. Sin embargo, el autor se encuentra plenamente consciente de las nuevas disposiciones adoptadas por la Iglesia Católica, tras el Concilio de Trento, con respecto al

${ }^{10}$ El pensamiento de Cervantes, Noguer, Barcelona, 1973, pp. 136-137.

11 Fernando de Rojas, La Celestina, ed. J. Golacheca, Jorge A. Mestas, Madrid, 2001, p. 208. 
matrimonio. Por lo tanto, se cuida de ni siquiera insinuar la posible conveniencia de que las jóvenes contrajeran matrimonio sin permiso de sus padres, como ocurría antes del Concilio. Como se sabe, el príncipe Arnaldo, antes de casarse con la hermana de Sigismunda, al final de la novela, asegura que necesita el beneplácito de su padre para hacerlo.

Cuando se concierta la boda de Transila, Mauricio se siente muy atormentado debido a una tradición de su pueblo en que los hermanos y demás parientes del novio suelen abusar sexualmente de la novia. Cabe recordar, como dato histórico, que, en la época medieval, el patrón tenía la primera noche con la novia: el antiguo derecho de la pernada. Debido a las amenazas de muerte que sufre por oponerse al acto, el viejo padre es incapaz de defender el honor de su hija. Ruth El Saffar acusa duramente al padre, así como al novio, de cobardes: "Transila, seeing her father's and fiancé's cowardice, takes her defense in her own hands and escapes her homeland by ship"12. Ella tiene que enfrentarse sola a quienes pretenden violarla. Este personaje se asemeja mucho al de Lucrecia en Fuenteovejuna de Lope de Vega, quien resulta violada por el Comendador ante la inacción tanto de parte su padre como del hombre que ama. Lucrecia se enfrenta a los hombres de su pueblo y, tras llamarlos cobardes y hasta 'maricones', se propone enfrentarse sola a su victimario. Transila huye en una embarcación, y su padre, gracias a sus conocimientos astrológicos, da finalmente con ella. Ladislao, el novio de Transila, sale tras ella también. A causa de la negativa de la joven a seguir con la violenta tradición de su pueblo, los tres escapan para siempre de allí. La huida de Transila, su padre y su novio resulta contraria a lo que ocurre en La Galatea, en la que los pastores se proponen defender la permanencia de la joven en su tierra.

Como se puede percibir, la relación entre padre e hija en $E l$ Persiles es muy especial. Lejos de pretender obligarla a cumplir con la bárbara tradición, Mauricio prefiere huir con ella de su tierra para siempre, aunque, como el padre de Leocadia, en La fuerza de la sangre, es incapaz de defender su honor. La debilidad de ambos padres acentúa el drama de la deshonra que sufren las hijas. Conviene tener presentes algunas de las duras palabras con las que Lucrecia, en Fuenteovejuna, se dirige a los hombres de su pueblo:

12 Beyond fiction: The recovery of the feminine in the novels of Cervantes, University of California Press, Berkeley, 1984, p. 137. 
¡Vive Dios, que he de trazar

que solas mujeres cobren

la honra de estos tiranos,

la sangre de estos traidores,

y que os han de tirar piedras,

hilanderas, maricones,

amujerados, cobardes,

y que mañana os adornen

nuestras tocas y basquiñas,

solimanes y colores! ${ }^{13}$.

Como ocurría con los casos de honor/honra en España, en la isla de Mauricio se considera normal este tipo de comportamiento: "Mauricio's narrative reveals him rationalizing his acceptance of a social myth that his natural sagacity recoils from" 14 . De todas maneras, el amor de Mauricio por su hija resulta incuestionable. Esta pareja, como Ricote y su hija, aun a pesar de todas sus limitaciones, representa un verdadero oasis ante las relaciones paterno-filiales que abundan en los textos cervantinos. Por otro lado, hay que señalar que, como en el caso de Ricote, Agi Morato (El Quijote), la reina Isabel de Inglaterra (La española inglesa) y la gitana vieja (La gitanilla) $)^{15}$, Mauricio es un personaje extranjero. Este padre es un bárbaro. Es decir, que Cervantes, nuevamente, otorga rasgos de padre extraordinario a un personaje ajeno a la cultura española. El escritor ha sido verdaderamente consistente en este aspecto.

Del mismo modo, la relación entre el rey Policarpo y sus dos hijas requiere atención especial. Nuevamente, el lector se encuentra con un padre que cría a sus hijas solo: “...he guardado, como has visto, las leyes de la viudez con toda puntualidad y recato" (Persiles, p. 136). Cervantes no desarrolla la relación entre Policarpo y su hija, Policarpa. La joven aparece muy poco en la novela y su participación activa es mínima. Por el contrario, Sinforosa es una joven apasionada, poseedora de una fuerte personalidad. No en balde, Policarpo recurre a ella para que lo ayude a conquistar el amor de Auristela. La relación entre Policarpo y Sinforosa es estrecha; se vuelven cómplices de sus respectivos amores: "Si tú vienes con mi parecer, no se me dará

13 Orión, México, 1969, f. 275v.

14 D. De Armas Wilson, Cervantes' Persiles y Sigismunda an allegory of the couple, tesis de doctorado, University of Denver, 1981, p. 183.

15 Cf. Miguel de Cervantes, Novelas ejemplares, Altaya, Barcelona, 1994. 
nada del qué dirán" (Persiles, p. 138). Por otro lado, resulta evidente que Sinforosa ha llenado el lugar de su difunta madre: "Después, joh hija mía!, que me faltó tu madre, me acogí a la sombra de tus regalos, cubríme con tu amparo, gobernéme por tus consejos" (Persiles, p. 137). Es una especie de esposa sustituta de su padre, sin que con esto se pretenda insinuar que, entre ellos, haya una relación incestuosa. Sencillamente, Sinforosa ha asumido el rol de la reina, esposa y madre ausente.

Hay que recordar que Allison Weber ${ }^{16}$ advierte que Agi Morato, padre de Zoraida, en El Quijote, convierte a su hija en una esposa sustituta, por lo que la joven tiene que abandonarlo para buscar su propio lugar. Probablemente, la estudiosa coincidiría en considerar que Sinforosa se encuentra en una posición muy parecida a la de Zoraida, con la diferencia de que la presencia de Auristela desplaza la atención del padre. Conviene aclarar que Policarpo piensa más en sus propios intereses que en los de su hija: "Con estas últimas palabras y con esta grande promesa paladeó el rey la esperanza de Sinforosa” (Persiles, p. 138). Del mismo modo, la joven aprovecha el enamoramiento de su padre en su beneficio. Sin duda, Policarpo y Sinforosa gozan de una relación paterno-filial de mutua conveniencia que, dicho sea de paso, parece poco usual en la obra cervantina. No hay otra pareja de padre e hija(o) que presente estas características en el resto de los textos. No da la impresión de que el amor sea la fuente principal de la unión entre ellos, sino, más bien, la complicidad y los intereses comunes. Sin embargo, no se puede afirmar que, por este motivo, Policarpo sea un mal padre para sus hijas sino, más bien, un hombre maduro que sucumbe a las tentaciones del amor sensual y busca el apoyo de su hija para sus propios fines.

Del mismo modo, las pretensiones de Policarpo de casarse con la joven Auristela recuerdan El celoso extremeño. Nuevamente, el lector se encuentra con el hombre mayor que desea casarse con una mujer mucho más joven. En este aspecto, Cervantes sigue la línea de autores como Bandello (la Novella quinta de la Primera parte), quienes se oponían a este tipo de uniones dispares. Sin embargo, la diferencia fundamental entre ellos es que Cervantes desarrolla el tema con mayor compasión y sentido de

16 "Padres e hijas: una lectura intertextual de «La historia del cautivo»", Actas del Segundo Coloquio Internacional de la Asociación de Cervantistas, Anthropos, Barcelona, 1991, pp. 425-431. 
humanidad, mientras que Bandello se burla cruelmente del viejo enamorado ${ }^{17}$. Aunque, en este caso, no se cumplen las expectativas de Policarpo, ya que Auristela no llega a casarse con él, se repite el aroma incestuoso de la novela anterior. Auristela, contemporánea de Sinforosa y Policarpa, hubiera pasado a ocupar el lugar de una hija más al lado del rey, especialmente porque hubiera sido muy difícil despojar a Sinforosa de su función de esposa y madre sustituta. La joven se hubiera encontrado no sólo bajo el yugo de su padre-esposo, sino también bajo el de su hijastra-madre. Sin duda, aquí hay, pues, una gran tensión latente.

Por otro lado, Cervantes ofrece otro tipo de pareja, la de una madre y su hijo: nada más y nada menos que al protagonista, Persiles, y su madre, la reina Eustoquia. En este caso, por primera vez en la obra cervantina, el gran ausente es el padre. Si bien en su primera obra, La Galatea, Cervantes enfrenta a los lectores con la ausencia de la madre -y es consistente en sus demás novelas-, ahora parece tomar un rumbo distinto, justo en la última. Julio Baena advierte la recuperación de la madre en esta novela: "Al reencontrar lo femenino, hemos reencontrado la máquina de parir: la madre, o sea, la generadora de lo masculino, de la flecha atentadora de toda quietud"18.

Conviene ir por partes. La verdadera identidad de los peregrinos se conoce en los últimos capítulos de la novela, así que la presencia de la reina Eustoquia se encuentra, necesariamente, muy limitada. Sin embargo, se puede afirmar que ella es quien pone en marcha los acontecimientos que culminan con el matrimonio de los protagonistas. La reina es la promotora de la peregrinación a Roma. Como señala Ruth El Saffar:

...the mother's path does not draw the son into the magma of uroboric bliss. Instead of inviting him back to the mother or Great Mother image, the human mother Eustoquia points beyond herself to a relationship to the feminine that is not regressive but in fact growth-enhancing ${ }^{19}$.

17 Stanislav Zimic, Las novelas ejemplares de Cervantes, Siglo xxi de España Editores, Madrid, 1996, p. 226.

18 El círculo y la flecha: principio y fin, triunfo y fracaso del Persiles, University of North Carolina Press, Chapel Hill, 1996, p. 133.

19 "Persiles' retort: An alchemical angle on the lovers' labors", Cervantes, 10 (1990), p. 25. 
Según la estudiosa, la reacción de la reina se diferencia totalmente de algunos episodios en El Quijote, donde las figuras maternas sustitutas protegen al caballero, atrayéndolo a una especie de espacio uterino simbólico. En el episodio del Caballero del Lago ${ }^{20}$, las ninfas del castillo bañan, alimentan y cuidan al caballero como si se tratara de un niño. El Saffar ha aleccionado acerca de la simbología maternal que encierra el episodio. Don Quijote añora refugiarse en un espacio protegido, es decir, regresar al orden imaginario donde impera la madre $^{21}$. Sin embargo, en este caso, ocurre algo completamente distinto. La reina, en vez de intentar proteger a su hijo atrayéndolo hacia sí -como se tiene oportunidad de ver en El Quijote-, lo anima a luchar por alcanzar la felicidad que desea, aunque esto implique que se aleje físicamente de ella. Parece que este cambio ocurre porque, en El Persiles, la madre real se encuentra presente, mientras que en El Quijote, se trata de procesos exclusivamente psicológicos. El caballero no cuenta en realidad con la presencia de la madre, sino que debe "crearla" o, mejor dicho, "sustituirla", mediante complejos procesos emocionales. Da la impresión de que la recuperación de la madre en esta obra supuso, entre otras cosas, la liberación del hijo de ataduras emocionales y psicológicas. Por más contradictorio que pueda parecer, lo cierto es que, en vez de propiciar la dependencia emocional del hijo, la presencia de la madre estimula un desarrollo psíquico saludable.

Por otro lado, la actitud de la reina no deja de parecer extraña, ya que defiende los intereses de su hijo menor por sobre los del mayor, a quien hubiera correspondido casarse con la joven: “...Persiles' mother Queen Eustoquia, who is little impressed with codes of honor when it comes to the health and well-being of her beloved son Persiles"22. Hasta el ayo de Persiles, quien lo considera como a un hijo, exclama que éste es: "querido de su madre sobre todo encarecimiento" (Persiles, p. 379). La propia madre admite su abierta preferencia por su hijo menor:

20 Miguel de Cervantes Saavedra, El ingenioso hidalgo don Quijote de la Mancha, Planeta, Barcelona, 1998, parte 1, cap. 50.

${ }^{21}$ Ruth El Saffar e Iris Zavala, "Elogio de lo que queda por decir: reflexiones sobre las mujeres y su carencia en Don Quijote", en Breve historia feminista de la literatura española, Anthropos, Barcelona, 1995, t. 2, pp. 285326.

${ }^{22}$ R. El SAffar, "Persiles' retort...”, p. 25. 
Eustoquia habló a Sigismunda, encareciéndole lo que se perdía en perder la vida Persiles, sujeto donde todas las gracias del mundo tenían su asiento, bien al revés del de Maximino, a quien la aspereza de sus costumbres en algún modo le hacían aborrecible (Persiles, p. 381).

Sin duda, la actitud de la madre puede herir la sensibilidad de algunos lectores, ya que pretende encarecer las virtudes de un hijo a expensas de los posibles defectos del otro. Actitud nada loable en una madre, pero no por eso inusual. Muchas madres manifiestan preferencias por unos hijos sobre los otros por las más diversas razones.

En el caso de Sigismunda, sus circunstancias familiares son parecidas a las de Persiles, en el sentido de que no tiene padre o, al menos, éste no se menciona en el texto. Sólo se hace referencia a la existencia de una hermana llamada Eusebia, como su madre, quien no se vuelve a mencionar en toda la obra. Su madre, la reina de Frislanda, temiendo que ocurriera una guerra en su territorio, envía a su hija con la reina Eustoquia con el propósito de protegerla. Sin embargo, el ayo de Persiles, con gran perspicacia, intuye que: "yo para mí tengo que no fue esta la ocasión principal de enviarla, sino para que el príncipe Maximino se enamorase della y la recibiese por su esposa" (Persiles, p. 380). Sólo en esta ocasión se menciona a la madre de Sigismunda en toda la novela; aparentemente, la relación entre ellas no es estrecha. La reina considera a su hija como un instrumento útil para alcanzar ciertas ventajas económicas y políticas. Tiene, pues, una relación utilitaria e interesada con su hija.

Cuando Sigismunda, por su parte, decide partir a Roma -un viaje largo y peligroso-, no pide permiso a su madre ni le informa acerca de su partida. Sin duda, es una extraña actitud en una princesa honesta y recatada como ella. Se sabe que, en Las etiópicas, Cariclea huye con Teágenes, pero lo hace con la avenencia de su consejero espiritual. Además, la sacerdotisa ha sido separada de sus padres desde el nacimiento. La única vez que vuelve a mencionarse algo de la familia de Sigismunda es al final de la novela, donde se dice que su hermana Eusebia se casará con el príncipe Arnaldo. Da la impresión de que, tras establecerse en el reino de Maximino, Sigismunda se convierte en una joven huérfana para todos los efectos. Hasta el momento, ningún crítico parece haberse interesado en ahondar en la "orfandad" de Sigismunda. En el contexto de la obra cervantina, la "orfandad" 
de la joven sigue la línea de la mayoría de los personajes-hijos: la ausencia del padre, de la madre o de ambos. Cabe recordar que personajes como don Quijote, la Sobrina y Marcela son huérfanos de ambos padres. Clara de Viedma, Zoraida y Galatea son huérfanas de madre, mientras que Persiles lo es de padre.

El caso de Sigismunda es el más significativo. La joven princesa, a pesar de tener madre y hermana, parece ser el personaje más solo de toda la producción cervantina. El resto de los personajes que carecen de uno o ambos padres siempre cuentan con alguna figura paterna o materna sustituta $o$, al menos, un amigo. Sigismunda se encuentra verdaderamente sola. Primero, su madre la envía lejos a vivir con una reina y sus dos hijos, quienes la pretenden. Luego, la reina Eustoquia pide a la joven que se decida por su hijo menor, y ésta parece aceptar, de primera intención, porque no tiene a quién acudir. La única persona que podría aconsejarla es la misma que la incita a comprometerse con Persiles. Después, se va de viaje acompañada solamente por el joven que la pretende. La única explicación razonable, aunque no resulta totalmente satisfactoria, es que Cervantes considerara que la "ausencia" de los padres facilitaría la movilidad de la joven. Esta circunstancia le otorgaría cierto grado de libertad para viajar y vivir una serie de aventuras que, de haber permanecido junto a su familia, no hubiera tenido. Tal vez, el autor únicamente deseaba soslayar el tema de la obediencia y el confinamiento que hubiera debido guardar la princesa. $\mathrm{O}$, posiblemente, Cervantes deseaba que, como don Quijote y su amada Dulcinea, Sigismunda fuera, tan solo, "hija de sus obras".

Por otra parte, aparece una pareja de madre e hijo, que es simbólica en la novela: la de doña Guiomar de Sosa y el polaco (parte 3). Como se sabe por su narración, el polaco se encuentra de visita en Lisboa y una noche, mientras camina por un callejón oscuro, tropieza con un joven. El tropiezo provoca una disputa entre ellos y el polaco mata al otro con su espada. Tras el incidente, el polaco huye y se refugia en una casa, donde le pide ayuda a la dueña para esconderse de las autoridades. Doña Guiomar acepta ayudarlo y lo esconde tras un tapiz. Al poco tiempo, llegan los guardias con el cadáver del hijo de la dama, quien había sido asesinado. Doña Guiomar llega a la conclusión de que el hombre escondido en su casa es el asesino de su hijo. Aunque le causa un profundo dolor lo ocurrido: "¡Ay venganza, y cómo me estás llamando a las puertas del alma!" (Persiles, p. 254), decide cumplir su palabra de ayudarlo: "La 
afligida madre... respondió llena el alma de generoso ánimo y de piedad cristiana" (Persiles, p. 255). La dama se deshace de los guardias y envía a su criada a llevar al fugitivo a un lugar seguro. El polaco le agradece profundamente su ayuda y le pide perdón por el terrible dolor que le causa al haberle arrebatado la vida a su hijo. Doña Guiomar lo perdona y le pide que se marche cuanto antes. El polaco cuenta a los peregrinos que jamás olvidará a una mujer tan extraordinaria como ella.

Sin duda, la acción de doña Guiomar es encomiable, así como un tanto increíble. Ella no sólo perdona al asesino de su hijo, sino que lo esconde de las autoridades. Por más insólita que pueda parecer esta caracterización, lo cierto es que Cervantes debió inspirarse en la sexta novela de los Hecatommithi de Giraldo Cintio, en la que una madre acoge al asesino de su hijo. La diferencia fundamental entre ambos escritores es que, mientras Cintio lleva el suceso hasta las últimas e improbables circunstancias, adoptando al asesino de su hijo, Cervantes se mantiene dentro de ciertos límites del arte y la verosimilitud. Américo Castro considera la actitud cervantina del perdón y la compasión como un rasgo erasmista ${ }^{23}$. En el Enquiridion o manual del caballero cristiano, Erasmo considera que el arma cristiana predilecta es la caridad, en todo sentido ${ }^{24}$. Aunque no se puede afirmar que la exaltación de los valores universales de la compasión, el perdón y la caridad son necesariamente de influencia erasmista, lo cierto es que Cervantes los promulga a lo largo de toda su obra; es decir, que comparte la creencia de que estos valores forman parte del verdadero espíritu cristiano. Por más inverosímil que parezca, Cervantes ofrece una muestra de nobleza y calidad humana difícil de imitar. Sin duda, doña Guiomar de Sosa es un personaje extraordinario.

Por otra parte, en la novela, aparece una familia 'tradicional' (padres e hijos): Antonio, Ricla y sus dos hijos, Antonio y Constanza (parte 1). Sólo se encuentra otra familia 'tradicional' en toda la obra cervantina: Sancho Panza, Teresa y sus hijos. Cuando Persiles y Sigismunda están en la isla de los bárbaros en calidad de prisioneros, conocen a Antonio y a su familia, quienes viven en una parte oculta de la isla. La familia los ayuda a escapar de sus captores, los alimenta y les da albergue. Al incendiarse la isla, la familia huye con los peregrinos. Anto-

23 El pensamiento de Cervantes, p. 296.

24 Enquiridion militiis christiani o Manual del caballero cristiano, 1503, p. 47. 
nio, de origen castellano, le cuenta a sus nuevos amigos las circunstancias de su llegada a la isla bárbara. Tras una serie de peripecias, éste llega a una zona despoblada de la isla, donde conoce casualmente a una jovencita bárbara llamada Ricla. Con el tiempo y la convivencia, la relación entre ellos se estrecha y terminan enamorándose: "Es, pues, el caso... que mis muchas entradas y salidas en este lugar le dieron bastante para que de mí y de mi esposo naciesen esta muchacha y este niño" (Persiles, p. 54). Antonio enseña a su esposa a hablar español, la bautiza y la instruye en la religión católica. Para Diana de Armas: "The theme of their story-sacral love and its offsprings — provides a counterweight to the myth of sexual union, founded on blood and power, which characterizes love in Barbary" ${ }^{25}$. El Saffar, por su parte, considera que esta pareja: "in their faith and natural prosperity, resemble Adam and Eve" 26 .

Los críticos coinciden en que el matrimonio de Antonio y Ricla, aunque no es canónico, representa el lado positivo de las relaciones entre un hombre y una mujer, ya que supera el estigma del pecado por la sexualidad inherente a los esposos. Algunos estudiosos consideran importante el hecho de que Antonio y su esposa comparten una relación igualitaria, ya que Ricla:

...who have stepped out of the traffic and claimed their cultural and linguistic agency not through sameness but through multiplicity and otherness. Ricla has both learned her husband's language and taught him her own, and her husband and the other characters listen to her $^{27}$.

La pareja más democrática de la obra cervantina surge en un espacio fuera de la civilización: una zona despoblada de una isla bárbara. Da la impresión de que Cervantes considera que la sociedad imposibilita el desarrollo óptimo de las relaciones de pareja y familiares, en general. Además, cabe mencionar que estos esposos son los padres de dos jóvenes nobles y valerosos: "symbolizing the fruits of the original wedding of spirit and matter" 28 , quienes acompañan a los protagonistas en su largo viaje. Cervantes parece sugerir que de padres ejemplares, hijos ejemplares.

25 Cervantes' Persiles y Sigismunda..., p. 174.

26 Beyond fiction..., p. 135.

27 E. Bergmann, art. cit., p. 11.

28 R. El SAFfar, Beyond fiction..., p. 135. 
Hasta el momento, se aprecian, en El Persiles, relaciones familiares variadas, pero esencialmente exitosas. En términos generales, la mayor parte de las figuras paternas y maternas resultan positivas, ya tanto las sustitutas como las reales. Por otro lado, las "brujas" o "magas" Cenotia (parte 2) y la esposa Zabulón (parte 4) no poseen la carga maternal negativa que el autor otorga a la Cañizares del Coloquio de los perros. La función de estos personajes se limita a traer al texto el tema de la magia y los poderes sobrenaturales como fuerzas negativas. No aparece en ellas ninguna referencia que apunte al símbolo o al conflicto de la maternidad.

En este punto, corresponde analizar dos situaciones relacionadas con la maternidad que presentan algunos rasgos particulares y complejos, pero con cierta semejanza entre sí: la historia de Feliciana de la Voz y el curioso nacimiento simbólico sin madre de Persiles. En la novela, una madre que se destaca, pero por su falta de instinto maternal, es Feliciana de la Voz. Esta historia intercalada sigue la tónica de las Novelas ejemplares, y recuerda a La señora Cornelia, ya que, en términos generales, trata sobre los amores prohibidos de una pareja de jóvenes nobles, que culmina con el nacimiento de una criatura. Periandro, Auristela y el resto de los peregrinos se encuentran con un hombre a caballo que, tras entregarles una cadena de oro, les pide que se hagan cargo de una criatura recién nacida. Al poco tiempo de irse el hombre, aparece una joven desesperada que les pide ayuda para esconderse de unas personas que la persiguen. Unos pastores, que están en los alrededores, la socorren y la colocan sobre unas mantas en el hueco de una encina; le dan sopas de leche y vino y la cubren con pieles (Persiles, p. 230). El narrador asocia la escena con sobretonos maternales: "preñada estaba la encina" (Persiles, p. 231). Sin duda, apropiadísima metáfora para efectos de este estudio. Diana de Armas ha dicho sobre este episodio que: "...is a nativity story whose focus is not on an infant's birth but rather on his mother's rebirth into the symbolic order, her acquisition of narrative voice and authority" ${ }^{29}$. Cervantes recrea este renacimiento simbólico de una forma muy original: los pastores (parteros) sacan a la criatura (la joven) de las entrañas de una encina (útero materno). Como se verá, este renacimiento no es el único que se efectúa sin la presencia física

29 Allegories of love. Cervantes Persiles and Sigismunda, Princeton University Press, New Jersey, 1991, p. 209. 
de la madre; lo mismo ocurre con Persiles. La misma Feliciana declara, abiertamente, el vacío materno que sufre: "que madre no la tengo, por mayor desgracia mía” (Persiles, p. 233). Da la impresión de que la joven pretende justificar de alguna manera su comportamiento, atribuyéndoselo a la ausencia de su madre.

$\mathrm{Al}$ otro día, la joven se identifica ante los pastores como Feliciana de la Voz, y procede a contarles su historia: cómo se había entregado por amor a un joven noble, quedando embarazada, y el consiguiente escándalo de su familia, ya que la tenían prometida en matrimonio a otro hombre. Los pastores le informan a la joven que tienen en su poder a un bebé que podría ser el suyo. Feliciana no puede reconocer a la criatura como a su hijo, ya que asegura que ni siquiera lo había visto al nacer. La joven pide a los peregrinos que le permitan acompañarlos en su camino. Hasta el momento, Feliciana no sólo es incapaz de identificar a su propio hijo, sino que se desentiende fácilmente de él: "Lleváronsela, miróla y remiróla, quitóle las fajas, pero en ninguna cosa pudo conocer ser la que había parido" (Persiles, p. 237). En vez de procurar buscar a la criatura desaparecida, decide irse en una peregrinación con un grupo de extraños. No se ha visto antes mayor desapego en una madre cervantina. Como ha notado Diana de Armas, "the explicit absence of that sentiment [woman-mother] in Feliciana" ${ }^{30}$. Hay que coincidir con De Armas Wilson en que Feliciana carece por completo de sentido maternal, a diferencia de la señora Cornelia, quien, a pesar de preocuparse por sus vicisitudes familiares y sociales, añora recuperar a su bebé desaparecido. Conviene recordar, además, las anagnórisis de La gitanilla y La ilustre fregona. El narrador no juzga la actitud de la joven en ningún momento, sólo se limita a describirla. En el caso de Feliciana, Cervantes desplaza el tema de la maternidad y se concentra en la transformación personal de la joven.

Por otro lado, cabe destacar que esta actitud del autor se diferencia, notablemente, de la de su modelo literario, Heliodoro. En Las etiópicas, se manifiesta una actitud muy distinta ante la maternidad:

la naturaleza materna es un conocimiento que no puede mentir, que hace que el que fue el engendrador, a la primera vista de los 
hijos se hincha de un afecto de conmiseración y amor por una secreta conformidad y conveniencia de naturaleza (pp. 367-368).

También Oriana, en El Amadís, abandona a su hijo y, luego, lo reconoce. En esta ocasión, Cervantes sacrifica el tema de la maternidad en aras de la autonomía y dignificación de la figura de la mujer. Se trata de un caso singularísimo en la literatura europea.

Otro aspecto del episodio de Feliciana que conviene mencionar es su encuentro con su padre y su hermano. Mientras visitan una iglesia, ella entona un himno en honor a la Virgen. Diana de Armas Wilson señala que la asociación de Feliciana con la Virgen no es un intento por establecer sus diferencias sino, más bien, todo lo contrario. Cervantes pretende recuperar la historia real de María, como mujer y madre, en oposición a la imagen cristiana de ella:

There is another view of Mary to consider. Implicit in Feliciana's story is the story of Mary's maternity: her anguished concealment of her pregnancy, her flight from the patriarch Herod's knife, and her delivery within the cold pastoral world of Christ's nativity ${ }^{31}$.

Según la estudiosa, con esta asociación simbólica Cervantes intenta mostrar la parte humana y femenina de María, a la que no suele tenerse acceso. La 'mala' madre acude a la protección de la 'súper' madre: lo que ella desearía completar en sí misma. Dicho esto, hay que regresar al análisis de la escena. Los familiares de Feliciana reconocen su voz. Su hermano se encuentra muy enojado y pretende matarla frente a todos para limpiar el honor de su familia: "Ella, es, y la que no lo será si no yerra el golpe este mi brazo" (Persiles, p. 244). El padre, más conciliador, aduce que los asuntos privados de la familia deben atenderse en privado:

No es éste, ¡oh hijo!, teatro de miserias ni lugar de castigar. Da tiempo al tiempo, que pues no se nos puede huir esta traidora, no te precipites, y, pensando castigar el ajeno delito, te eches sobre ti la pena de la propia culpa (Persiles, p. 245).

Conviene tomar en cuenta que, en El Quijote, don Diego de Miranda afirma que mejor no hubiera engendrado a su hijo

31 Allegories of love..., p. 213. 
Lorenzo. Sin embargo, por más cruel que estas palabras puedan sonar, las que ha dicho el padre de Feliciana con respecto a ella son peores.

Los peregrinos y los pastores deciden evitar que los dos hombres se lleven a Feliciana. Esta escena posee un paralelo simbólico con La Galatea: los pastores interceden ante los airados familiares de la joven, quien finalmente es "devuelta" a su familia. (No hay que olvidar que los pastores pretenden evitar la partida de Galatea de su tierra.) En ese momento, llega un grupo de personas, entre ellos el padre del hijo de Feliciana, quien explica la situación a la familia de la joven, pide excusas y permiso para casarse con ella. La joven hace lo propio: "Arrodillóse también ante su padre Feliciana, derramó lágrimas, envió suspiros, vinieron desmayos"32. Los familiares deciden perdonar la afrenta. El bebé, que era el mismo que Feliciano no había reconocido antes como suyo, se encuentra ya con su padre. De hecho, el antes vengativo abuelo, cuando ve al bebé: “...tomándole en sus brazos, tiernamente le bañó el rostro con sus lágrimas, y se las enjugó con besos, y las limpió con sus canas" (La Galatea, p. 247). Esta escena ejemplifica el estricto código del honor que impera en la sociedad cervantina, que el teatro de la época refleja tan vivamente. Sin embargo, es la primera vez, en la narrativa de Cervantes, que la familia manifiesta explícitamente su intención de hacer pagar a la joven por la deshonra que les ha causado. De hecho, no lo llevan a cabo debido a la pronta oposición de los peregrinos y los pastores, así como a la aparición de su "esposo". Cervantes es incapaz de llegar tan lejos en su representación y resuelve el conflicto, hay que admitir, de forma un tanto inverosímil, pero fiel a los principios de su sociedad, en la que el perdón, el amor y la comprensión lo pueden todo.

A pesar de que se trata de la primera escena de la novela, el "nacimiento de Persiles" representa, por su parte, una alegoría tan rica y compleja que conviene atenderla, cuidadosamente, en la parte final de este estudio. La novela comienza con la salida de Persiles de una cueva, donde se encontraba prisionero de los bárbaros. Corsicurvo, un bárbaro, da voces al fondo de la cueva a una prisionera llamada Cloelia para que envíe al joven prisionero. El bárbaro lanza al fondo de la mazmorra una soga de la que atan al prisionero y lo suben a la superficie. Esta escena recuerda, inmediatamente, la salida de don Quijote de la

${ }^{32}$ Cátedra, Madrid, 1995, p. 246. 
Cueva de Montesinos. Julio Baena (op. cit.) describe en detalle cómo se estructura la alegoría del nacimiento y lleva su interpretación hasta las últimas consecuencias. Las voces de Corsicurvo representan los gritos de la madre, que escucha la también prisionera Cloelia ( $i$ acaso se entienden porque se trata de 'cosas de mujeres'?). El bárbaro lleva a cabo, entonces, una función de madre y comadrona. La cueva, en este caso, hace las veces de un espacio uterino, mientras que la estrecha salida de la cueva es la vagina. Las ataduras del joven no son otra cosa que el cordón umbilical que lo mantiene unido a la madre. Persiles no sale de la cueva, lo sacan como a un niño, es decir, que es un sujeto pasivo; sin duda, se trata de un parto simbólico. Cuando sacan al joven sucio y mojado, los bárbaros (parteros) se disponen a encargarse de las ataduras y a limpiar el cuerpo, como ocurre con las criaturas recién nacidas. Finalmente, el joven (bebé) pronuncia unas palabras de agradecimiento por haberlo sacado de la mazmorra. Estas palabras, que resultan sonidos inteligibles para los bárbaros, simbolizan el primer llanto de la criatura. El nacimiento de Persiles mediante el parto supone la existencia de una madre biológica. De hecho, tanto Baena como De Armas, han advertido la relación de la palabra trabajo del título de la novela con el trabajo que supone el parto: "Desde el Génesis, parto es la cara femenina de la divina maldición de trabajar" (ibid., p. 48). Como han dicho De Armas y Baena, a diferencia de $E l$ Quijote, esta obra representa tanto la fertilidad como la posición de la madre en un primer plano. Es decir que: “...parto es la cara del nacimiento que mira a la madre, a la mujer" (id.).

Hasta el momento, hay que coincidir con Baena en su interpretación de la escena inicial de la novela. Sin embargo, el estudioso considera que el texto cuenta con un cuerpo femenino (cueva) que no necesariamente implica la presencia de una mujer real. Además, Baena afirma que la búsqueda de esa mujer se extenderá a lo largo de todo el texto y que permanecerá inconclusa con la alusión a los futuros nietos de los protagonistas. Es decir, que dicha búsqueda continuará más allá del final de la novela. Partiendo de esta línea interpretativa se puede proponer que la búsqueda cervantina de la mujer culmina efectivamente en esta novela póstuma. La mujer/madre se encuentra nada más y nada menos que en una "encina preñada". Evidentemente, la mujer/madre no puede ser Sigismunda, por dos razones poderosas. En primer lugar, la virginidad de la joven se manifiesta desde el inicio de la novela y se hace hinca- 
pié en ella constantemente. En segundo lugar, si se sigue de cerca el patrón alegórico de la novela, ella sería la hermana gemela de Persiles, papel que pretende desempeñar a lo largo de la novela. Lo más lejos que el autor llega a visualizar a la joven en capacidad de madre es al final donde, si bien se espera que tenga hijos en el futuro, el asunto no llega a materializarse, por lo menos, en el texto. Por lo tanto, la mujer/madre cervantina del Persiles no es otra que Feliciana de la Voz, quien ha dejado de ser doncella para convertirse en madre.

Como afirma De Armas, Feliciana es la mujer que representa a María la Virgen en calidad de mujer: su embarazo, su parto, su fuga, la pérdida final de su hijo. Feliciana representa, también, la imagen desculpabilizada de la maternidad, ya que el nacimiento del niño (la vida misma) es capaz de borrar el más terrible de los pecados. Si Sigismunda es la virgen, pura y casta, Feliciana es la mujer realizada en todas sus facetas: la maternal y la femenina. Se podría argumentar contra esta interpretación, el "desapego" de la joven con respecto a su hijo, pero lo cierto es que no se puede ser plenamente madre sin ser plenamente mujer. Esta joven es la figura materna, a quien el autor, y los lectores con él, siguen la pista a lo largo de los textos. Al fin, se da con ella, aunque sin duda se trata de una madre desnaturalizada. Cervantes no parece ser aquí capaz de elaborar una familia completa y armónica. Esta proposición, si bien da la impresión de ser "moderna", no esconde el horror de que una madre no reconozca ni busque a su hijo recién nacido.

Sin duda, Los trabajos de Persiles y Sigismunda no sólo ofrece una amplia gama de figuras paternas y maternas, sino que también representa el desarrollo y, en ocasiones, la transformación de varias de estas construcciones a lo largo del conjunto de textos prosísticos cervantinos. Como en el resto de estas obras, son comunes las parejas de padres e hijas. En este caso, se encuentran también, por excepción, las de madres e hijos. Una familia "tradicional", como la de los Panza en El Quijote, completa su desarrollo óptimo en la familia de Antonio y Ricla. Curiosamente, las figuras paternas o maternas sustitutas son escasas en esta novela, a diferencia de lo que sucede en El Quijote y en las Novelas ejemplares. Otra diferencia en esta obra es que las "brujas" o "magas" que aparecen no tienen la carga de maternidad negativa de la Cañizares del Coloquio de los perros.

En términos generales, estas relaciones paterno-filiales son bastante positivas en relación con lo que se observa en el con- 
junto de la obra cervantina. Por otro lado, aparecen dos escenas de nacimientos sin madre: la de Persiles y la de Feliciana de la Voz. La búsqueda de la madre que se emprende desde La Galatea parecería concluir con el nacimiento simbólico de Feliciana, la madre y mujer tan anhelada por su autor. No obstante, esta interpretación debe ser matizada. La aparición del personaje de Feliciana en la obra cervantina no resuelve definitivamente el conflicto de la ausencia de la madre, aunque tal vez sí el conflicto de la ausencia de la mujer. Los "nacimientos" de don Quijote, Persiles y Feliciana (una cueva, una mazmorra y un árbol) evidencian que la figura materna sigue ausente: se trata de cavidades vacías. Para poder convertirse plenamente en la mujer, Feliciana sacrifica a la madre que hay en ella. Da la impresión de que no es posible conciliar ambas funciones: mujer o madre, pero no ambas.

Como se aprecia a lo largo de la narrativa cervantina, la búsqueda infatigable de la madre desde La Galatea resulta una constante difícil de ignorar, que alcanza momentos verdaderamente oscuros con la presentación de personajes terribles como la bruja Cañizares. Sin embargo, como afirma Baena, esta búsqueda optimista se proyecta más allá de los textos: en los futuros hijos de Persiles y Sigismunda. Ante la dificultad de encontrarla, Cervantes deja que esta madre se mantenga como un deseo no satisfecho. Como afirma don Quijote con respecto a Dulcinea, cuya existencia se le escapaba entre los dedos, así Cervantes ha podido afirmar acerca de la madre: "estas no son de las cosas cuya averiguación se ha de llevar hasta el cabo".

Sylma García González Universidad de Puerto Rico 